\title{
Reduction in Crosstalk Using Uniform Germanium Strips for Dense Integration of Photonic Waveguides
}

\section{Veer Chandra ( $\nabla$ veer.ecpg16@nitp.ac.in )}

National Institute of Technology Patna https://orcid.org/0000-0003-4159-0169

Dablu Kumar

NIT Patna: National Institute of Technology Patna

Rakesh Ranjan

NIT Patna: National Institute of Technology Patna

\section{Research Article}

Keywords: Photonic waveguide, Germanium strip, Coupling length, Crosstalk.

Posted Date: July 16th, 2021

DOI: https://doi.org/10.21203/rs.3.rs-714338/v1

License: (c) (i) This work is licensed under a Creative Commons Attribution 4.0 International License.

Read Full License 


\title{
Reduction in Crosstalk using Uniform Germanium Strips for Dense Integration of Photonic Waveguides
}

\author{
Veer Chandra, Dablu Kumar, and Rakesh Ranjan \\ OFC and Photonics Research Lab, \\ Department of Electronics and Communication Engineering, \\ National Institute of Technology Patna, India. \\ *E-mail: veer.ecpg16@nitp.ac.in, dablu.ece15@nitp.ac.in, rr@nitp.ac.in
}

\begin{abstract}
The requirement of low crosstalk between the neighboring waveguides should be considered essentially, in order to achieve the compact photonic integrated circuit (PIC), which includes photonic waveguides. Literature shows that the lower crosstalk can be realized by using the silicon-on-insulator (SOI) based waveguide, having an appropriate separation between them. The current work is focused on reducing the waveguide separation to further improve the photonic integration over the PICs. This has been achieved by inserting the germanium strips between the photonic waveguides. The investigations of the impact of variations in heights and widths of germanium strip have demonstrated that the crosstalk can be reduced by a significant amount, which provides noteworthy improvement in coupling length. The maximum coupling lengths of $81578 \mu \mathrm{m}, 67099 \mu \mathrm{m}$, and 66810 $\mu \mathrm{m}$ have been achieved at their respective end-to-end separations of $300 \mathrm{~nm}, 250 \mathrm{~nm}$, and $200 \mathrm{~nm}$, and their corresponding minimum crosstalk values have been noted as $-29.40 \mathrm{~dB},-27.71 \mathrm{~dB}$, and $-27.70 \mathrm{~dB}$. Moreover, the analysis to realize the coupling length for Ge-strip, have been compared with the Si-, and $\mathrm{SiN}$-strips. The approach presented in the current work can be utilized for the design of many compact photonic applications, such as polarization splitter, integrated photonic switches, etc.
\end{abstract}

Keywords: Photonic waveguide, Germanium strip, Coupling length, Crosstalk.

\section{Introduction}

Photonic waveguides and its related devices are attracting more and more attention due to its high bandwidth capabilities, very less propagation delay time, and smaller size. Different structures of photonic waveguide, such as strip, rib, and slot waveguide, can be used for different applications [1-2]. The realization of dense photonic integration is essentially required for the efficient and compact design of photonic integrated circuits (PICs), where the array of waveguides is closely placed [3-4]. However, due to the reduced spacing, a part of the field may have coupled in the adjacent waveguides, resulting in higher crosstalk (CT) on the array of waveguides. Hence, the reduction of the crosstalk between the nearby waveguides is a crucial and challenging issue to produce the compact and dense PICs [5]. Recently, many authors have proposed different techniques to reduce the crosstalk between the photonic waveguides [6-7]. The authors in [7] have presented the approach of subwavelength silicon gratings technique for the photonic waveguide, to control the guided light in PICs, and hence, to reduce the crosstalk. The silicon gratings show the high index, in the direction parallel to the interface. This leads to the fast decay of evanescent field, which is leaked from the waveguide core. Following this principle, the investigations of the three subwavelength strips between the two adjacent waveguides have been done in [8], to improve the crosstalk performance. The authors have demonstrated the negligible crosstalk for the waveguide spacing of $350-500 \mathrm{~nm}$, at the wavelength of $1.55 \mu \mathrm{m}$. Further, many applications based on coupling phenomena of compact waveguide devices have been reported recently in literature, such as polarization/mode converters [9-10], ultra-sharp waveguide bends [11], integrated photonic switches [12], etc. The current work focuses to investigate the mode characteristics of the silicon waveguide, to comprehend its performance in terms of crosstalk, and scalability. The analysis has been done for the end-to-end waveguide separation of $200 \mathrm{~nm}$ to $300 \mathrm{~nm}$. In [8], the authors have reported the coupling length of $1000 \mu \mathrm{m}$, with the waveguide spacing of $300 \mathrm{~nm}$. However, in the current work, by using the three uniform germanium strips with their height variations, the coupling length up to $81578 \mu \mathrm{m}$, has been obtained for the same waveguide spacing. Further, with lower waveguide spacing of $200 \mu \mathrm{m}$, the coupling length up to $66810 \mu \mathrm{m}$ has been obtained, which ultimately demonstrates very low crosstalk, and hence, dense photonic integration over the PICs. 


\section{Design structure and parameters}

\subsection{Design of proposed structure}

The design of the proposed structure has been illustrated in Fig. 1, which consists of two adjacent ridge waveguides with three germanium strips inserted between them. The widths of core of ridge waveguide, and inserted strips have been denoted respectively as, $w_{1}$, and $w_{2}$; whereas, their respective heights are considered as $\mathrm{h}_{1}$, and $\mathrm{h}_{2}$. The end-toend distance between waveguides, and the strip gaps have been assumed respectively as, $\mathrm{g}_{1}$ and $\mathrm{g}_{2}$; while, the distance between ridge waveguide to strip has been kept as $\mathrm{g}_{2}$, Moreover, for the mode analysis, the height of strips have been varied. The material used for core of ridge waveguide is silicon and same for the strip is germanium, with their respective refractive indices of 3.45 and 4.21, at the operating wavelength of $1.55 \mu \mathrm{m}$ [13-14]. Moreover, other material also has been used for strips for comparison of results, such as, Si and SiN, where SiN have the refractive index of approx.1.9 at the operating wavelength of $1.55 \mu \mathrm{m}$. Further, the refractive index contrast in $\mathrm{Si}$-Air-Si based structure is quite lower than that in Si-Air-Ge based structure, which is beneficial for achieving the higher coupling length.

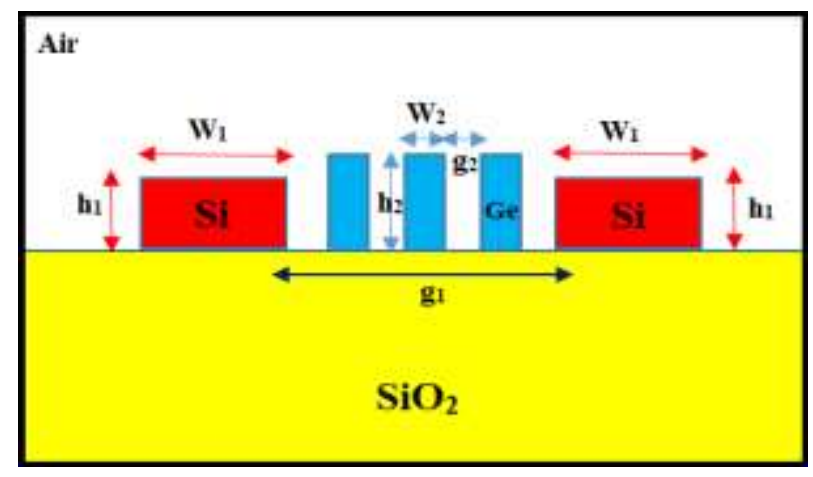

Fig. 1 Basic design structure of strip waveguide with over-cladding area

\subsection{Coupling length}

The directional couplers are essentially used for the power transfer from one waveguide to another [10]. However, by keeping a sufficient separation between the adjacent waveguides, the extent of power transfer can be reduced, and it can act as an individual waveguide. The coupling length $\left(L_{c}\right)$ can be described as a length over which the optical power is fully transferred from one waveguide to the adjacent waveguide, and it can be expressed as [15],

$$
L_{c}=\frac{\lambda}{2\left(n_{s}-n_{a}\right)}
$$

where, $n_{s}$ and $n_{a}$ are the real part of the mode indices, respectively for the symmetric and antisymmetric modes, and $\lambda$ is the operating wavelength.

\subsection{Propagation length}

The propagation length is highly reliant on the imaginary part of the effective refractive index, i.e., $\operatorname{Im}\left(n_{\text {eff }}\right)$, of the guided mode. It can be defined as a length of waveguide over which the propagating power drops to 1/e of its total power, and can be expressed as [15],

$$
\text { Propagation length }=\frac{\lambda}{4 \pi \times \operatorname{Im}\left(n_{e f f}\right)}
$$

\subsection{Crosstalk (CT)}

The closely placed photonic waveguides over the PICs, may cause the overlap of mode fields, and hence, the crosstalk [16-17] between them. Therefore, the investigations on crosstalk performance between the two adjacent photonic 
waveguides, is essentially required to achieve the high photonic integration in the photonic chip. The crosstalk between two adjacent photonic waveguides can be estimated as [15-16],

$$
\operatorname{Crosstalk}(C T)=10 \log _{10}\left[\sin \left(\frac{\pi L_{0}}{2 L_{c}}\right)\right]^{2}
$$

where, $L_{0}$ is the propagation distance, and $L_{c}$ is the coupling length, which is reliant on the gap between waveguides and the waveguide dimensions. It has been observed that with a larger gap between waveguides, a larger coupling length can be achieved, after the propagation distance, and hence, introduces a smaller crosstalk [16]. Therefore, in this work, the main focus is to realize the significantly larger coupling length.

\section{Simulation results}

The modal investigations have been done using the finite element method (FEM) based COMSOL Multiphysics simulation platform. To discretize the waveguide geometry model, the extremely fine mesh size has been considered. Further, to address the losses during the mode propagation, the scattering boundary condition has been applied.

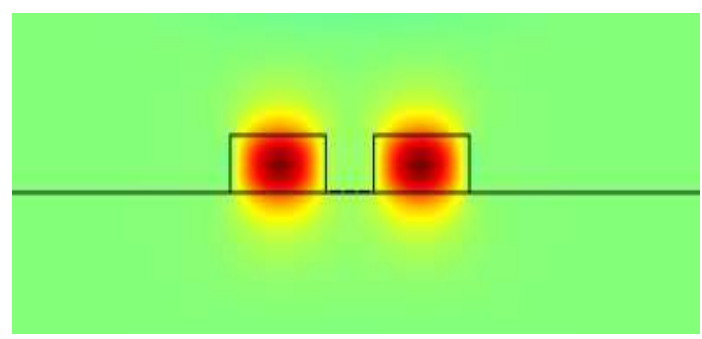

(a)

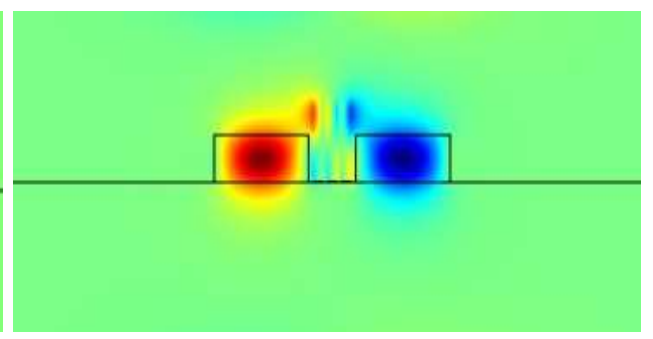

(b)

Fig. 2. Electric field distributions for (a) symmetric, and (b) antisymmetric modes, at $g_{1}=250 \mathrm{~nm}$ for $w_{2}=30 \mathrm{~nm}$, and $h_{2}=$ $380 \mathrm{~nm}$

The electric field distributions along the y-direction, for both symmetric and antisymmetric modes, have been depicted respectively in Figs. 2 (a), and (b), at $g_{1}=250 \mathrm{~nm}, w_{2}=30 \mathrm{~nm}$ and $h_{2}=380 \mathrm{~nm}$. Similar mode distributions have also been obtained with the other considered values of width $\left(w_{2}\right)$ and height $\left(h_{2}\right)$, for the analysis of various modal characteristics in the subsequent subsections. The width $\left(w_{1}\right)$ and height $\left(h_{1}\right)$ of ridge waveguide are fixed respectively at $500 \mathrm{~nm}$, and $220 \mathrm{~nm}$. Moreover, the strip width $\left(w_{2}\right)$ and strip gap $\left(g_{2}\right)$ are related with the relationship of $3 w_{2}+4 g_{2}=g_{1}$. In this work, three different cases of end-to-end waveguide separations $\left(g_{1}\right)$ of $300 \mathrm{~nm}, 250$ $\mathrm{nm}$, and $200 \mathrm{~nm}$, with $w_{2}=30 \mathrm{~nm}$, and $50 \mathrm{~nm}$, have been considered for the extensive analysis.

\subsection{Coupling length $\left(L_{c}\right)$ analysis using Ge strip}

In order to study the performance of coupling length, initially end-to-end waveguide separation $\left(g_{1}\right)$ has been assumed as $300 \mathrm{~nm}$, with two considered values of strip width $\left(w_{2}\right)$ of $30 \mathrm{~nm}$, and $50 \mathrm{~nm}$. To obtain the values of coupling length, for $g_{1}=300 \mathrm{~nm}$, the height $\left(h_{2}\right)$ of all the Ge-strips have been varied uniformly up to $400 \mathrm{~nm}$. Figures 3(a) to 3(c) show the variations in coupling length in terms of height $\left(h_{2}\right)$, for both the considered values of $w_{2}$. From the Fig. 3 (a), it is clear that the values of the coupling length increase and attains a peak value at $h_{2}=233 \mathrm{~nm}$, and $154 \mathrm{~nm}$, respectively for $w_{2}=30 \mathrm{~nm}$, and $50 \mathrm{~nm}$. Their respective peak values of coupling length have been observed as $38557 \mu \mathrm{m}$, and $62500 \mu \mathrm{m}$, that are comparatively very high values. After that it decreases with the increasing values of $h_{2}$. During the simulations, it has been established that for $w_{2}=45 \mathrm{~nm}$, the coupling length has been achieved as $81578 \mu \mathrm{m}$, at $h_{2}=164 \mathrm{~nm}$. Therefore, it clearly demonstrates that for end-to-end waveguide separation of $300 \mathrm{~nm}$, one can achieve a very high coupling length. 


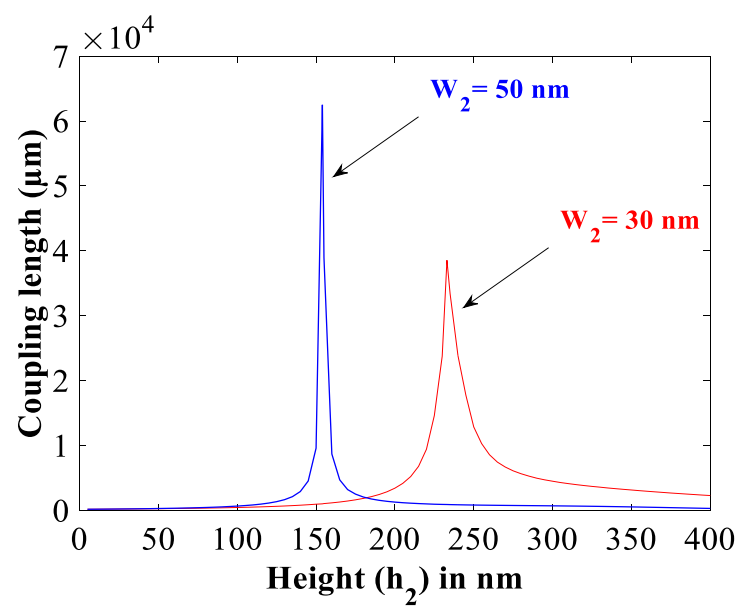

(a)

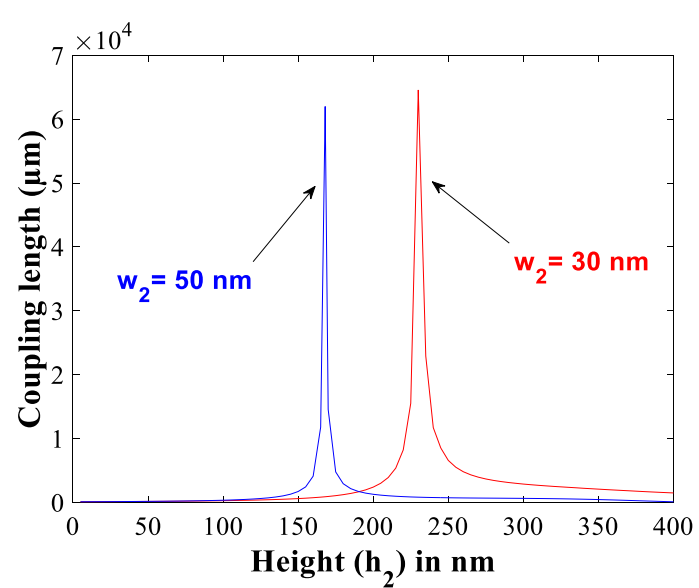

(b)

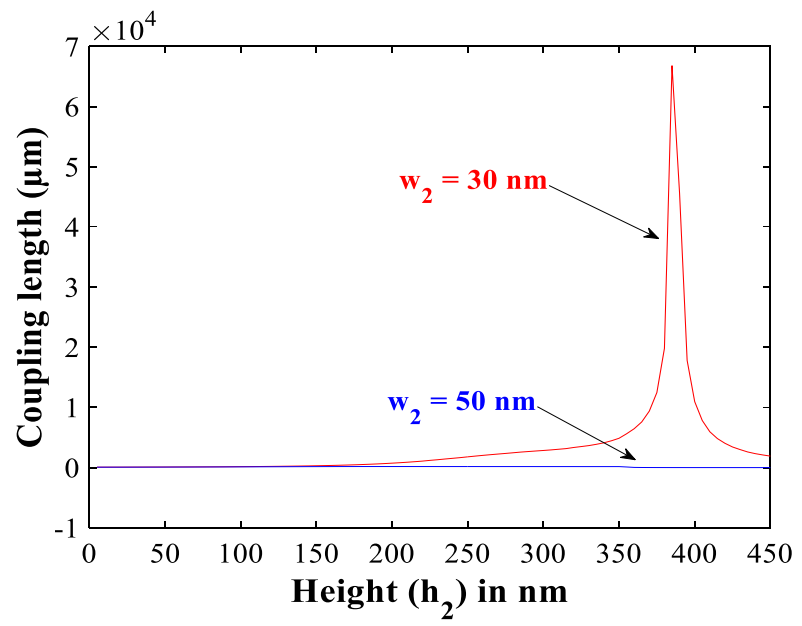

(c)

Fig. 3. Relationship between coupling length and Ge-strip height, for $w_{2}=30 \mathrm{~nm}$, and $50 \mathrm{~nm}$ at (a) $g_{1}=300 \mathrm{~nm}$, (b) $g_{1}=$ $250 \mathrm{~nm}$, and (c) $g_{1}=200 \mathrm{~nm}$

It has been observed that the variations in coupling length follows the similar trend, as depicted in Fig. 3c of Ref. [8], for the similar values of strip height $\left(h_{2}\right)$. Further, the similar analysis, for $g_{1}=250 \mathrm{~nm}$, have been done by varying $h_{2}$ uniformly up to $400 \mathrm{~nm}$, for $w_{2}=30 \mathrm{~nm}$, and $50 \mathrm{~nm}$. The relationship between the coupling length and $h_{2}$ has been estimated, and plotted in Fig. 3(b) for $g_{1}=250 \mathrm{~nm}$. Once again, the coupling length varies in the same fashion, and attains a peak value at $h_{2}=230 \mathrm{~nm}$, and $168 \mathrm{~nm}$, respectively for $w_{2}=30 \mathrm{~nm}$, and $50 \mathrm{~nm}$. However, their corresponding peak values of coupling length have been achieved respectively as, $64583 \mu \mathrm{m}$, and $62000 \mu \mathrm{m}$, which are comparatively lower values, as achieved for $g_{1}=300 \mathrm{~nm}$. However, again for $w_{2}=45 \mathrm{~nm}$, the higher coupling length of $67099 \mu \mathrm{m}$ has been obtained, at $h_{2}=171 \mathrm{~nm}$.

Furthermore, it has been observed that the mode propagation is considerably affected by the suitable choice of height and width of germanium strip. This also causes to change their respective effective refractive index values, and hence, the coupling length. The variations of coupling length with respect to $h_{2}$, for $g_{1}=200 \mathrm{~nm}$, has been depicted in Fig. 3(c). It has been observed that, for the lower strip width, i.e., $w_{2}=30 \mathrm{~nm}$, the light can propagate, and the peak coupling length can attend the value of $66810 \mu \mathrm{m}$ at $h_{2}=385 \mathrm{~nm}$. Whereas, for $w_{2}=50 \mathrm{~nm}$, light propagation is not significant, which results in extremely low value of coupling length, up to $\sim 182 \mu \mathrm{m}$, as illustrated in Fig. 3(c). 


\subsection{Coupling length $\left(\mathrm{L}_{\mathrm{c}}\right)$ analysis using $\mathrm{Si} / \mathrm{SiN}$ strip}

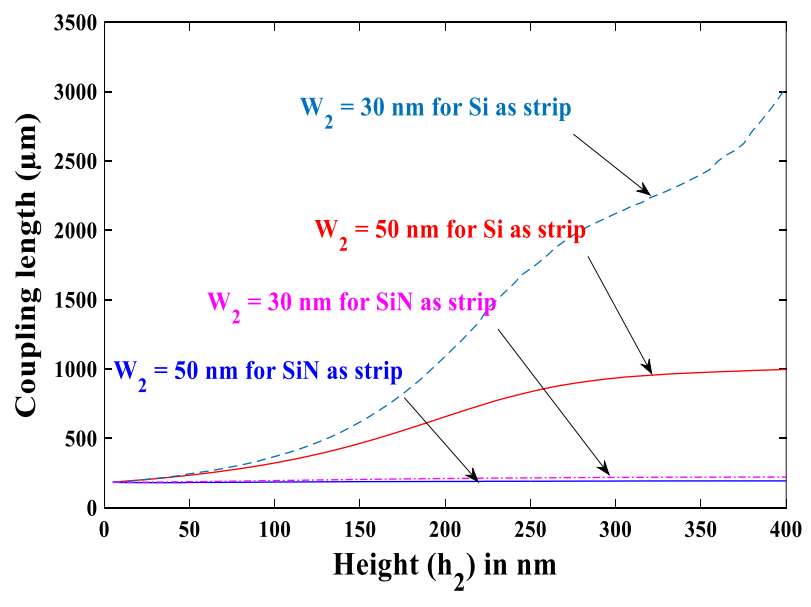

(a)

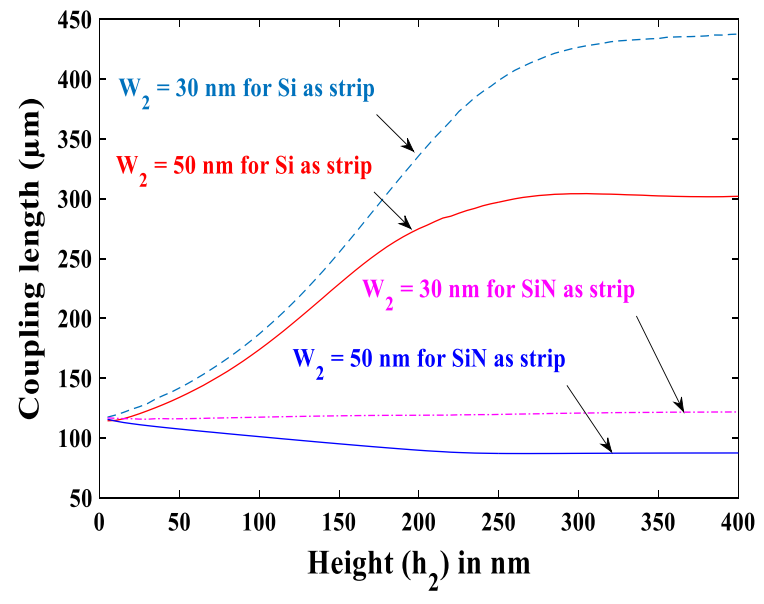

(b)

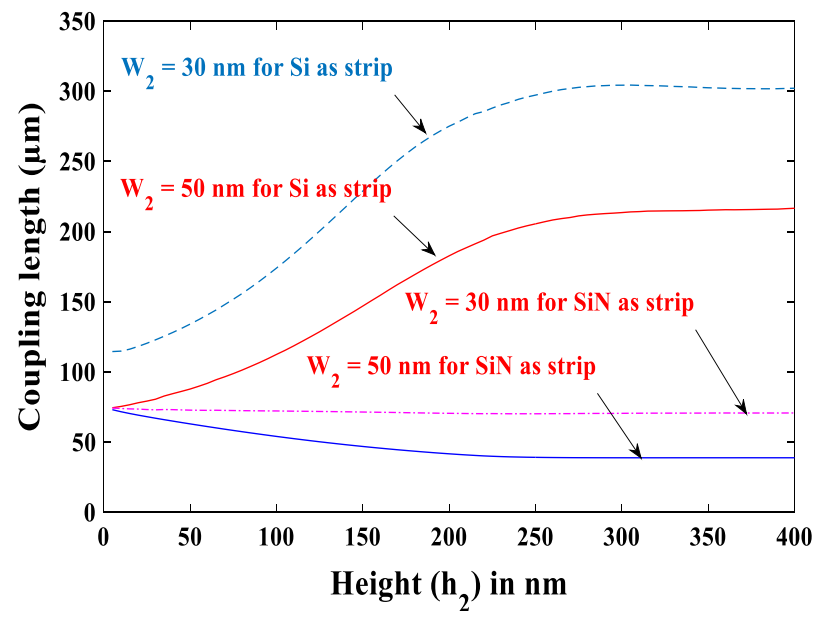

(c)

Fig. 4. Relationship between coupling length and $\mathrm{Si} / \mathrm{SiN}$ strip height, for $w_{2}=30 \mathrm{~nm}$, and $50 \mathrm{~nm}$ at (a) $g_{1}=300 \mathrm{~nm}$, (b) $g_{1}=$ $250 \mathrm{~nm}$, and (c) $g_{1}=200 \mathrm{~nm}$

Similarly, the analysis of variations in coupling length have also been done for Si- and SiN-strips, instead of Ge-strip, which is placed between two silicon waveguide, and depicted in Figs. 4 (a), (b), and (c) respectively, for $g_{1}=300 \mathrm{~nm}$, $250 \mathrm{~nm}$, and $200 \mathrm{~nm}$. Again, the variations in coupling length with respect to the strip heights $\left(h_{2}\right)$ have been observed for the same values of strip widths, i.e., $w_{2}=30 \mathrm{~nm}$, and $50 \mathrm{~nm}$. The figures clearly demonstrate that the coupling length is varying slowly, and attains the peak value, as obtained with Ge-strip. Here, for the Si-strip, larger coupling lengths have been observed as compared to the SiN-strip. The corresponding maximum values of coupling lengths for the Si-strip are $3029 \mu \mathrm{m}$, and $997 \mu \mathrm{m}$, and for the SiN-strip are $220 \mu \mathrm{m}$, and $193 \mu \mathrm{m}$, respectively at $w_{2}=30 \mathrm{~nm}$, and $50 \mathrm{~nm}$ for $g_{1}=300 \mathrm{~nm}$. Similarly, for $g_{1}=250 \mathrm{~nm}$, the corresponding maximum values of coupling lengths for Si-strip have been obtained as $437 \mu \mathrm{m}$, and $302 \mu \mathrm{m}$, and for SiN-strip, it have been achieved as, $87 \mu \mathrm{m}$, and $121 \mu \mathrm{m}$, at their respective $w_{2}=30 \mathrm{~nm}$, and $50 \mathrm{~nm}$. While, for $g_{1}=200 \mathrm{~nm}$, the corresponding maximum values of coupling lengths for Si-strip are $216 \mu \mathrm{m}$, and $302 \mu \mathrm{m}$, and the same for SiN-strip are $74 \mu \mathrm{m}$, and $73 \mu \mathrm{m}$, at their respective $w_{2}=30 \mathrm{~nm}$, and $50 \mathrm{~nm}$. These analyses clearly show that the coupling lengths for Gestrip have very high values, as compared that with $\mathrm{Si} / \mathrm{SiN}$ strips. Therefore, the obtained results have established that 
the proposed approach for introducing uniform Ge-strips, can be used as a promising technique to suppress the crosstalk between two neighboring photonic waveguides.

\subsection{Propagation length analysis using Ge strip}

The values of propagation length have been estimated by using the Eq. (2), and depicted in Figs. 5 (a), (b), and (c) respectively, for $g_{1}=300 \mathrm{~nm}, 250 \mathrm{~nm}$, and $200 \mathrm{~nm}$, for the Ge-strips between the photonic waveguides. The variations in the propagation length with respect to the strip heights $\left(h_{2}\right)$ have been observed for the same values of strip widths, $w_{2}=30 \mathrm{~nm}$, and $50 \mathrm{~nm}$. The figures clearly illustrate that the increase in $h_{2}$, leads to the decrease in propagation length, for all the considered values of $g_{1}$. However, a small change in propagation length pattern can be observed at the peak value of coupling length.

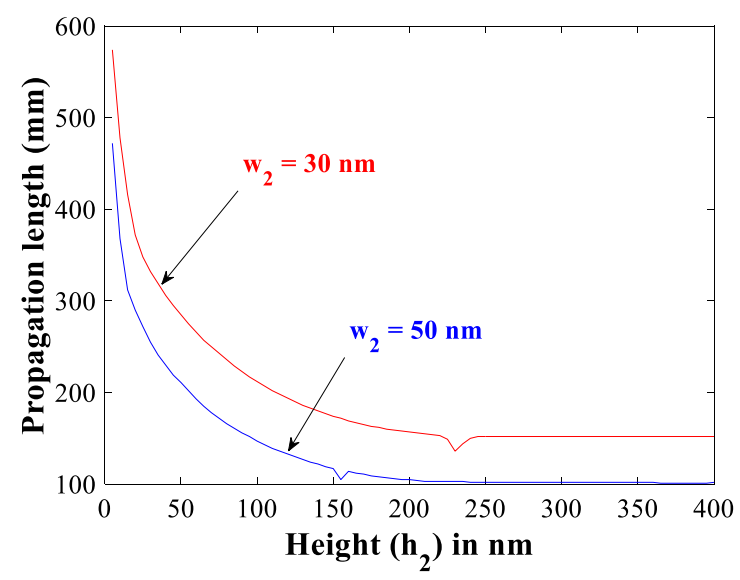

(a)

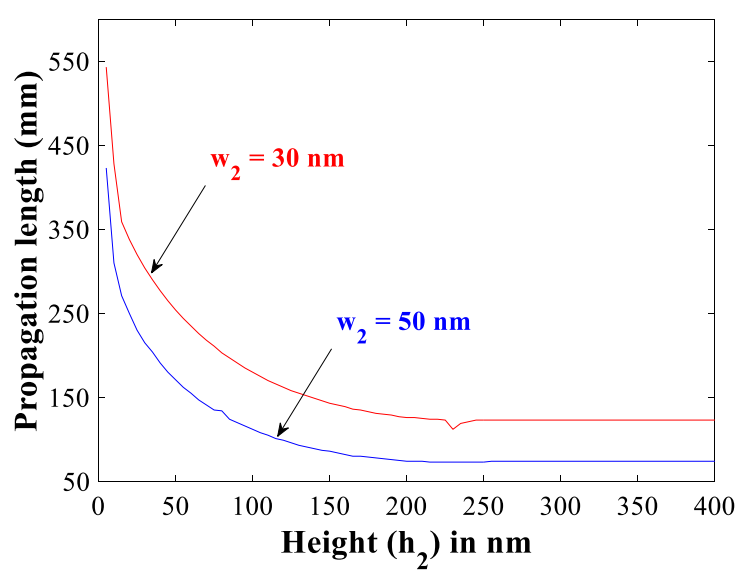

(b)

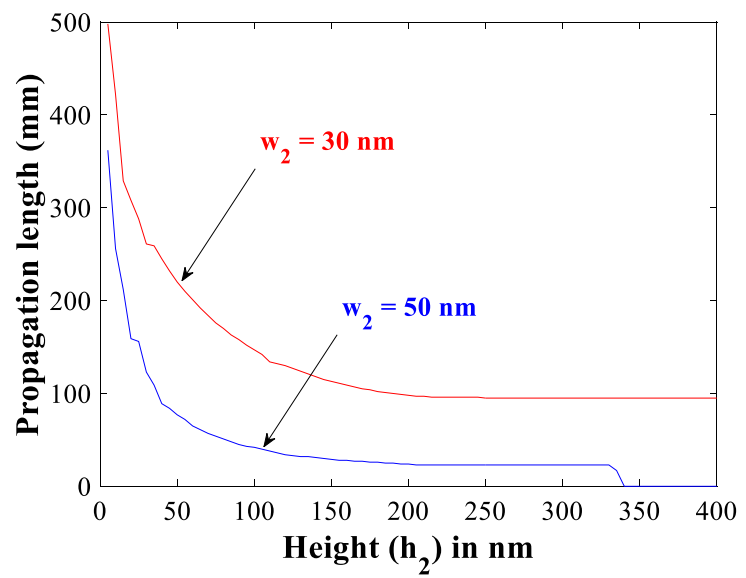

(c)

Fig. 5. Relationship between propagation length and Ge-strip height, for $w_{2}=30 \mathrm{~nm}$, and $50 \mathrm{~nm}$ at (a) $g_{1}=300 \mathrm{~nm}$, (b) $g_{1}=$ $250 \mathrm{~nm}$, and (c) $g_{1}=200 \mathrm{~nm}$

For $g_{1}=300 \mathrm{~nm}$, Fig. 5 (a) depicts that the propagation lengths are $115 \mathrm{~mm}$, and $144 \mathrm{~mm}$, respectively at $h_{2}=$ $233 \mathrm{~nm}$, and $154 \mathrm{~nm}$, where the peak coupling lengths have been achieved. Whereas, for $g_{1}=250 \mathrm{~nm}$, the propagation length have been noted as $112 \mathrm{~mm}$, and $72 \mathrm{~mm}$, at their respective strip heights $\left(h_{2}\right)$ of $230 \mathrm{~nm}$, and 168 $\mathrm{nm}$. While, for $g_{1}=200 \mathrm{~nm}$ and $w_{2}=30 \mathrm{~nm}$, the propagation length is only $87 \mathrm{~mm}$, at the point of peak coupling length, i.e., $h_{2}=385 \mathrm{~nm}$. Moreover, for $w_{2}=50 \mathrm{~nm}$ with $g_{1}=200 \mathrm{~nm}$, it can be observed that the propagation length is quite lower, and after $h_{2}=340 \mathrm{~nm}$, it attains nearly zero value, which is mainly due to the non-propagation of mode. Whereas, with $w_{2}=30 \mathrm{~nm}$, light can confine adequately, and provides a moderate propagation length with high coupling length. 


\subsection{Crosstalk analysis using Ge strip}

The values of crosstalk between the Ge-strip based photonic waveguides, can be calculated by using the Eq. (3), where, it can be observed that crosstalk is reliant on propagation distance and coupling length. Here, the propagation length $\left(L_{0}\right)$ has been assumed as $100 \mathrm{~mm}$. The minimum crosstalk for $g_{1}=300 \mathrm{~nm}$ has been obtained as $-29.40 \mathrm{~dB}$, at a point of coupling length of $81578 \mu \mathrm{m}$. While, $g_{1}=250 \mathrm{~nm}$, it is nearly obtained as $-27.71 \mathrm{~dB}$, which is corresponding to the coupling length of $67099 \mu \mathrm{m}$. However, for strip width $\left(w_{2}\right)$ of $30 \mathrm{~nm}$ with $g_{1}=200 \mathrm{~nm}$, the similar crosstalk level of $-27.70 \mathrm{~dB}$ has been obtained, at the corresponding point of coupling length of $66810 \mu \mathrm{m}$. Moreover, the waveguide separation, corresponding to the crosstalk, $\leq-30 \mathrm{~dB}$, can be considered as the decoupled separation [16], at which the negligible crosstalk can be obtained between the nearby photonic waveguides.

\section{Discussion and comparison}

As the crosstalk of photonics waveguides is directly reliant on the coupling length. Therefore, the main objective of the current work is to get higher coupling length with the smaller separation between the waveguides. In order to achieve the higher coupling length, three germanium strips have been used between the neighboring photonic waveguides and analyzed the influence of their height variations. The maximum coupling lengths of $81578 \mu \mathrm{m}, 67099$ $\mu \mathrm{m}$, and $66810 \mu \mathrm{m}$ have been observed, at their respective waveguide separations of $300 \mathrm{~nm}, 250 \mathrm{~nm}$, and $200 \mathrm{~nm}$. Previously, many authors have reported different (lower) coupling lengths for the similar kinds of structures. Table I shows the comparison of coupling length of the proposed design structure based on three germanium strip, with the previously reported structures. In [8], authors have reported $1000 \mu \mathrm{m}$ of coupling length at $300 \mathrm{~nm}$ of separation between waveguides, while in the current work, it has been observed $81578 \mu \mathrm{m}$ with same waveguide separation of $300 \mathrm{~nm}$. Therefore, the proposed approach of introducing uniform Ge-strips, can be utilized as a promising approach to suppress the crosstalk between two adjacent photonic waveguides, and hence, to achieve the dense photonic integration over the PICs.

Table 1: Comparison of coupling length of the proposed design structure with previously reported results

\begin{tabular}{|c|c|c|c|}
\hline Sr. No. & Reported work & Coupling length & Remarks \\
\hline 1. & $2020[8]$ & $1000 \mu \mathrm{m}$ & Separation $=300 \mathrm{~nm}, 3$ Si-strips \\
\hline 2. & $2018[3]$ & $4000 \mu \mathrm{m}$ & $\begin{array}{l}\text { Centre-to-Centre separation }=1000 \mathrm{~nm}, \mathrm{w}=475 \mathrm{~nm} \\
\quad 5 \mathrm{Si} \text {-strips }\end{array}$ \\
\hline 3. & 2017 [18] & $8500 \mu \mathrm{m}$ & Separation $=500 \mathrm{~nm}, 2$ Si-strips \\
\hline 4. & $2017[18]$ & $332000 \mu \mathrm{m}$ & Separation $=500 \mathrm{~nm}, 3$ Si-strips \\
\hline 5. & 2016 [7] & $3880 \mu \mathrm{m}$ & Separation $=500 \mathrm{~nm}, 2$ Si-strips \\
\hline 6. & Proposed work & $81578 \mu \mathrm{m}$ & $\begin{array}{c}g_{1}=300 \mathrm{~nm} \text { for } w_{2}=45 \mathrm{~nm}, \text { and } h_{2}=164 \mathrm{~nm} \\
3 \mathrm{Ge} \text {-strips }\end{array}$ \\
\hline 7. & Proposed work & $67099 \mu \mathrm{m}$ & $\begin{array}{c}g_{1}=250 \mathrm{~nm} \text { for } w_{2}=45 \mathrm{~nm}, \text { and } h_{2}=171 \mathrm{~nm} \\
3 \mathrm{Ge} \text {-strips }\end{array}$ \\
\hline 8. & Proposed work & $66810 \mu \mathrm{m}$ & $\begin{array}{c}g_{1}=200 \mathrm{~nm} \text { for } w_{2}=30 \mathrm{~nm}, \text { and } h_{2}=385 \mathrm{~nm} \\
3 \text { Ge-strips }\end{array}$ \\
\hline
\end{tabular}

\section{Conclusion}

In this paper, the influence of uniform germanium strips between the adjacent integrated photonic waveguides, have been demonstrated to achieve the lower crosstalk for the compact photonic devices. The maximum coupling lengths of $81578 \mu \mathrm{m}, 67099 \mu \mathrm{m}$, and $66810 \mu \mathrm{m}$ have been achieved, at their respective waveguide separations of $300 \mathrm{~nm}$, $250 \mathrm{~nm}$, and $200 \mathrm{~nm}$, which shows the significant improvement as compared to recently reported works. The lower crosstalk in the range of $-27 \mathrm{~dB}$ to $-29 \mathrm{~dB}$ have been realized with the proposed waveguide structure, which is beneficial to accomplish the dense photonic integrated platform. Further, the analysis for realizing the coupling length for Ge-strip, have been compared with other strips, such as Si- and SiN-strips. These studies state that the Ge-strip 
have superior coupling length as compared with $\mathrm{Si} / \mathrm{SiN}$ strips. Moreover, the dimension of the proposed structure can be further optimized to enhance the device performance in terms of crosstalk, and coupling length. The approach presented in the current work can be beneficial for the development various application, such as integrated photonic switches, ultra-sharp waveguide bends, etc.

Author Contributions All authors are equally contributed in the manuscript.

Data Availability I reused existing data.

Conflict of Interest The authors declare that they have no conflicts of interest.

Consent for Publication Not Applicable.

Consent to Participate Not Applicable.

Compliance with Ethical Standards This article does not contain any studies involving animals or human

participants performed by any of the authors.

Funding Statement No Funding was received

\section{Acknowledgments}

The authors gratefully acknowledge, National Institute of Technology Patna, and Science and Engineering Research Board, Department of Science and Technology, Government of India for providing COMSOL Multiphysics simulation software, used in the current simulation work.

\section{References}

1. Singh, R., Priye, V. (2021) $\mathrm{Si}_{3} \mathrm{~N}_{4}-\mathrm{SiO}_{2}$ based curve slot waveguide for high confinement factor and low mode effective area along with biosensing application. Silicon: https://doi.org/10.1007/s12633-020-00927-y

2. Chandra, V., Ranjan, R. (2021) Modelling and simulation of reduced height strip type nanophotonic waveguide using $\mathrm{Si}_{3} \mathrm{~N}_{4}$ as cladding material for filter applications. Silicon: https://doi.org/10.1007/s12633-021-00997-6

3. Jahani, S., Kim, S., Atkinson J., et al. (2018) Controlling evanescent waves using silicon photonic all-dielectric metamaterials for dense integration. Nature Communications 9(1893): 1-9

4. Cerutti, I., Andriolli, N., and Velha, P. (2017) Engineering of closely packed silicon-on-isolator waveguide arrays for mode division multiplexing applications. Journal of the Optical Society of America B 34(2): 497-506

5. Song, W., Gatdula, R., Abbaslou S., et al. (2015) High-density waveguide superlattices with low crosstalk. Nature Communications 6(7027): 1-9

6. Donzella, V., Fard, S. T., and Chrostowski L. (2013) Study of waveguide crosstalk in silicon photonics integrated circuits. Proc. SPIE 8915, Photonics North 2013, Ottawa, Canada, 89150Z

7. Khavasi, A., Chrostowski, L., Lu Z., and Bojko R. (2016) Significant crosstalk reduction using all-dielectric CMOScompatible metamaterials. IEEE Photonics Technology Letters 28 (24): 2787-2790

8. Yang, Y., Guo, Y., Huang, Y., et al. (2020) Crosstalk reduction of integrated optical waveguides with nonuniform subwavelength silicon strips. Scientific Reports 10(4491): 1-8

9. Wang, H., Zhang Y., et al. (2019) Compact silicon waveguide mode converter employing dielectric metasurface structure. Adv. Opt. Mater. 7(4): 1801191

10. Ohana, D., Desiatov, B., Mazurski, N. and Levy, U. (2016) Dielectric metasurface as a platform for spatial mode conversion in nanoscale waveguides. Nano Lett. 16(12): 7956-7961

11. Wu, H., Li C., et al. (2019) Ultra-sharp multimode waveguide bends with subwavelength gratings. Laser \& Photonics Rev. 13(2): 1800119

12. Wu, C., Yu H., et al. (2019) Low-loss integrated photonic switch using subwavelength patterned phase change material. ACS Photonics 6(1): 87-92

13. Kim, S., Han, J., Shim, J., Kim, H., and Choi, W. J. (2018) Verification of Ge-on-insulator structure for a mid-infrared photonics platform. Optical Materials Express 8 (2): 440-451

14. Amotchkina, T., Trubetskov, M., Hahner, D., and Pervak, V. (2020) Characterization of e-beam evaporated Ge, YbF3, ZnS, and LaF3 thin films for laser-oriented coatings. Applied Optics 59(5): A40-A47

15. Kumar, P., Singh, D. K., Ranjan, R. (2020) Optical performance of hybrid metal-insulator-metal plasmonic waveguide for low-loss and efficient photonic integration. Microwave Optical Technology Letter 62(4): 1-9

16. Dai, D., Shi, Y., and He, S. (2007) Comparative study of the integration density for passive linear planar light-wave circuits based on three different kinds of nanophotonic waveguide. Applied Optics 46(7): 1126-1131

17. Kumar D., Ranjan R. (2018) Optimal design for crosstalk analysis in 12-core 5-LP mode homogeneous multicore fiber for different lattice structure. Optical Fiber Technology 41: 95-103

18. Bian, Y., Ren Q., et al. (2017) Efficient cross-talk reduction of nanophotonic circuits enabled by fabrication friendly periodic silicon strip arrays. Scitific Reports 7(15827): 1-9 